OPEN ACCESS ISSN 2528-4649 (online) ISSN 2338-4409 (print)

${ }^{*}$ Correspondence:

Received: 7 Agustus 2019 Accepted: 27 November 2019

Published: 4 Maret 2020

Citation:

Wulanfitri E, S and Indayani L (2020) Pengaruh Job Insecurity, Kepuasan Kerja dan Stres Kerja Terhadap Turnover Intention dengan Komitmen Organisasi Sebagai

Variabel Intervening pada PT Lumina Packaging.

Pengaruh Job Insecurity, Kepuasan Kerja dan Stres Kerja Terhadap Turnover Intention dengan Komitmen Organisasi Sebagai Variabel Intervening pada PT Lumina Packaging . 6:1. doi: http://doi.org/10.21070JBMP.

V6/1.425

\section{Pengaruh Job Insecurity, Kepuasan Kerja dan Stres Kerja Terhadap Turnover Intention dengan Komitmen Organisasi Sebagai Variabel Intervening pada PT Lumina Packaging}

\author{
Eki Wulanfitri, Sumartik, Lilik Indayani \\ Fakultas Bisnis Hukum dan IImu Sosial, Universitas Muhammadiyah Sidoarjo
}

The research to examine Influence of Job Insecurity, Job Satisfacction and Job Stress on Tunover Intention with Organitational Commitment as Intervening Variable. This research uses a quantitive approach with a survey method. Uses simple random sampling technique. The population amounted 291 employees and the sample is 75 employees of PT Lumina Packaging. Technical data analysis using PLS with Warppls 5.0 software. The result found that Job Insecurity have an indirect effect on Turnover Intention through Organitational Commitment as an intervening variable by $47 \%$, Job Satisfactiion have an indirect effect on Turnover Itention through Organitational Commitment as an intervening variable $42 \%$, Job Stress have an indirect effect on Turnover Intention through Organitational Commitment as an intervening variable by $43 \%$.

Keywords - Job Insecurity, Job Satisfaction, Job Stress, Turnover Intention, and Organitational Commitment

Keywords: Job Insecurity, Job Satisfaction, Job Stress, Turnover Intention, Organitational Commitment

Tujuan penelitian ini yaitu menguji pengaruh dari Job Insecurity, Kepuasan Kerja dan Stres Kerja terhadap Turnover Intention melalui Komitmen Orgnisasi sebagai Variabel Intervening. Menggunnakan pendekatan kuantitatif metode survei dan teknik simple random sampling. Populasi berjumlah 291 karyawan dan sampel yang digunakan berjumlah 75 karyawan PT Lumina Packaging. Teknis analisis data menggunakan PLS dengan software Warppls 5.0. Hasilnya menemukan bahwa Job insecurity berpengaruh scara tidak langgsung terhadap Turnover Intention melalui Komitmen Organisasi sebagai variabel intervening sebesar 47\%, Kepuasan Kerja berpengaruh secara tidak langsung terhadap Turnover Intention melaui Komitmn Organisasi sebagai variabel intervening sebesar 42\%, dan Stres Kerja berpengaruh secaraa tidak langsung terhadap Tunover Intention melalui Komitmen Organisasi sebagai variabel intervening sebesar 43\%.

Kata Kunci - Job Insecurity, Kepuasan Kerja, Stres Kerja, Turnover Intention, dan Komitmen Organisasi

Keywords: Job Insecurity, Job Satisfaction, Job Stress, Turnover Intention, Organitational Commitment 


\section{PENDAHULUAN}

Tenaga kerja atau SDM merupakan aset utama yang dimiliki oleh sebuah perusahaan, tanpa manusia yang bekerja maka sumber daya lainnya di dalam perusahaan tidak akan dapat dimaksimalkan untuk mendapatkan laba (Elmi, 2018: 195). Dalam perkembangan industri modern, peran SDM di dalam perusahaan tidak terlepas dari penggunaan teknologi pada setiap pekerjaanya. Dalam hal ini adalah penggunaan mesin-mesin dengan kapasitas tertentu yang mampu memproduksi barang pada suatu perusahaan. Penggunaan mesin - mesin didalam perusahaan lebih efektif dan efisien.

Selain faktor perkembangan teknologi dalam sektor industri modern, faktor internal lain yang sering ditemui dalam perusahaan yaitu adanya sistem kontrak bagi karyawan oleh perusahaan. Karyawan kontrak adalah karyawan yang tidak memiliki atau bukan karyawan tetap pada suatu perusahaan yang bekerja pada suatu waktu berdasarkan kesepakatan karyawan dengan tempat mereka bekerja.

Job insecurity merupakan ketidakamanan kerja. Tetapi tidak mengarah pada kesehatan, keselamatan dan keamanan kerja karyawan, akan tetapi lebih mengarah pada keberlanjutan masa depan dari pekerjaan seorang karyawan yang bersangkutan. Adanya perkembangan industri ditambah dengan pemberlakuan sistem kontrak ini yang biasanya membuat karyawan merasa tidak aman dan menimbulkan kecemasan akan status pekerjaan mereka di masa depan (Greenhalgh \& Rosenblatt, 1984) dalam (Iskandar \& Yuhansyah, 2018: 2).

Kepuasan kerja adalah sikap seorang karyawan dalam mengahadapi pekerjaannya, yang timbul karena penilaian terhadap pekerjaanya yang dilakukan sebagai bentuk penghargaan dalam pencapaian nilai pada pekerjaannya. (Umam, 2018:192).

Stres kerja merupakan suatu tekanan emosional pada seorang karyawan yang menghadapi tuntutan-tuntutan besar pada pekerjaannya, berbagai hambatan yang dapat mempengaruhi kondisi fisik, emosi, serta pikiran, seseorang Effendi (2002) dalam Ida Bagus \& Ardana (2017). Beban kerja dan dikarenakan perkembangan teknologi yang ada yang dapat memicu adanya stres kerja.

Turnover intention adalah suatu keinginan tenaga kerja untukk keluar dari organisasi ataupun perusahaanya, mengarah pada kenyataan akhir yang harus dihaadapi oleh perusahaan berapa tenaga kerja yang meniinggalkan perusahaan dalam suatu waktu tertenntu (Elmi, 2018:195).

Komitmen organisasi merupakan bentuk penerimaan oleh seseorang terhadap nilai-nilai serta tujuan dari sebuah perusahaan, dengan demikian seseorang tersebut berkarya dan serta berhasrat untuk tetap bertahan di perusahaan tersebut (Baron dan Greenberg, 1990) dalam Umam (2018).

Penelitian ini dilakukan pada PT Lumina Packaging. PT Lumina Packaging pertama didirikan pada tahun 2011 di Trosobo - Sidoarjo, Provinsi Jawa Timur. PT Lumipack adalah perusahaan yag bergerak di bidang industri kemasan (flexible packaging). PT Lumina Packaging memproduksi beberapa jenis kemasan.

Namun, PT Lumina Packaging ini merupakan salah satu perusahaan yang menerapkan sistem karyawan kontrak. Perusahaan ini memiliki total 291 karyawan dengan 73 karyawan tetap, sementara 218 karyawan kontrak, dengan gap yang cukup jauh ini berpotensi memicu adanya job insecurity dan ketidakpuasan dalam bekerja karena karyawan merasa cemas dan tidak aman akan keberlanjutan masa depan pekerjaan mereka. Penggunaan mesin-mesin berteknologi tinggi juga yang berpotensi menimbulkan stres kerja mengingat tidak semua karyawan memiliki kecakapan yang sama dalam hal pengoperasian mesin-mesin.

Keadaan seperti diatas dapat memicu terjadinya turnover karyawan. Sedangkan tingkat komitmeen organisasi yang dimiliki karyawan dapat menentukan apakah seorang karyawan pada akhirnya memutuskan untuk mencari pekerjaan baru atau mencari alternatif pekerjaan lain diluar perusahaan ini. Dibawah ini data turnover karyawan PT Lumina Packaging dalam 3 tahun terakhir 2017-2019 sebagai berikut :

Sumber : HRD PT Lumina Packaging

Berdasarkan tabel yang telah dipaparkan diatas, prosentase turnover karyawan pada tahun 2017 10,4\% sedangkan pada tahun 2018 mengalami penurunan 0,4\% menjadi sebesar 10\% dan 
TABLE 1 | Data Turnover karyawanPT Lumina Packaging Tahun 2017-2019

\begin{tabular}{lllll}
\hline \multirow{2}{*}{ Thn } & Jumlah Karyawan & Karyawan & Karyawan & Jumlah Kryawan \\
& Awal Tahun & Masuk & Keluar & Akhir Tahun \\
2017 & 248 & 39 & 27 & 260 \\
2018 & 260 & 59 & 29 & 290 \\
2019 & 290 & 32 & 31 & 291 \\
\hline
\end{tabular}

pada tahun 2019 mengalami peningkatan 0,7\% sehingga menjadi sebesar 10,7\%. Pemberlakuan atau penetapan sistem kontrak pada karyawan yang berpotensi menimbulkan job insecurity dan ketidakpuasan dalam bekerja karena para karyawan merasa status kepegawaiannya dalam perusahaan belum menemui kejelasan. Adanya perkembangan teknologi pada industri modern saat ini yang memicu adanya stres kerja karena tidak semua karyawan memiliki pemahaman yang sama akan teknologi. Mengacu pada permasalahan, maka peneliti menetapkan judul "Pengaruh Job Insecurity, Kepuasan Kerja dan Stres Kerja Terhadap Turnover Intention dengan Komitmen Organisasi Sebagai Variabel Intervening pada PT Lumina Packaging” yang beralamat di Trosobo, Sidoarjo.

Hipotesis pada penelitian ini sabagai berikut :

Terdapat pengaruh sacara tidak langsung Job Insecurity terhadap Turnover Intentionn melalui komitmen organissasi sebagai variabell intervening pada PT Lumina Packaging

Terdapat peengaruh secara tidak langsung Kepuuasan Kerja terhadaap Turover Intention melalui komitmen organiasi sebagai variabel intervening pada PT Lumina Packaging

Terdapat pengaru secara tidak lansung Stres Kerja terhadap Turnover Itention melalui Komitmen Oganisasi sabagai variabel intervening pada PT Lumina Packaging

\section{METODE PENELITIAN}

Penelitian ini mengunakan metode kuantitatif dan metode survey, dilakukan pada perusahaan kemasan yaitu PT Lumina Packaging yang beralamat di Trosobo No. KM 23,6 Tanjung, Trosobo, Kecamatan Krian, Kabupaten Sidoarjo, Provinsi Jawa Timur 61262. Telp 031-8971777.

Populasi adalah 291 karyawan PT Lumina Packaging, sampel penelitian ini sebanyak 75 karyawan menggunakan tingkat kepercayaan sebesar 10\%. Teknik pengambilan sampel simple random sampling. Sumber data primer diperoleh pada penelitian ini didapat melalui wawancara, penyebaran kuisioner dan observasi langsung pada lapangan. Data sekunder yang didapat berupa company profile, data jumlah karyawan tetap dan karyawan kontrak serta data turnover karyawan selama 3 tahun terakhir. Teknik analisis data menggunakan PLS melalui software Warppls 5.0.

\section{HASIL DAN PEMBAHASAN}

\section{Pengujian kualitas data}

Uji validitas

uji validitaas dilihat berdasarkan nilai AVE (Average Variance Extraced) yang mengharuskan lebih besaar dari 0,5

TABLE 2 | Hasil nilai AVE

\begin{tabular}{lllll}
\hline \multicolumn{5}{l}{ Average variances extracted } \\
\hline$X^{1}$ & $X^{2}$ & $X^{3}$ & $Z$ & $Y$ \\
0.507 & 0.518 & 0.556 & 0.619 & 0.588 \\
\hline
\end{tabular}

Sumber: hasil nilai AVE pada pengujian Warppl 5.0

Dari tabel diatas dapat diketahui bahwa dalam penelitian ini nilai AVE pada variabel job insecurity (X1) sebesar 0.507, kepuasan kerja (X2) sebesar 0.518, stres kerja (X3) sebesar 0.556, komitmen organisasi $(\mathrm{Z})$ sebesar 0.619 dan turnover intention $(\mathrm{Y})$ sebesar 0.588 masing-masing variabel dikatakan valid karena memiliki nilai Average Variance Extraced (AVE) lebih dari (> 
$0.5)$ pada masing-masing variabel.

Uji reliiabilitas

Uji reliiabilitas ditentukan berdasarkan Internal Consitency Reliability dengan melihat Composite Reiability harus lebih besar dari 0,7.

TABLE 3 | Nilai Composite Reliability

\begin{tabular}{lllll}
\hline \multicolumn{5}{l}{ Composite reliability coefficients } \\
\hline$X^{1}$ & $X^{2}$ & $X^{3}$ & $Z$ & $Y$ \\
0.768 & 0.748 & 0.762 & 0.829 & 0.789
\end{tabular}

Sumber: hasil nilai composite reliability Warppls 5.0

Dari tabel diketahui nilai composite reliability variabel job insecurity (X1) yaitu 0.768, kepuasan kerja (X2) yaitu 0.748 , stres kerja (X3) yaitu 0.762 , komitmen organisasi $(\mathrm{Z})$ yaitu 0.829 dan variabel turnover intention (Y) yaitu 0.789 lebih besar dari 0.7 yang berarti nilai data dari variabel $\mathrm{X} 1, \mathrm{X} 2, \mathrm{X} 3, \mathrm{Y}$ dan $\mathrm{Z}$ memiliki reliabilitas yang baik atau dapat dikatakan nilai masing-masing variabel adalah reliabel.

\section{Pengujian inner model (model struktural)}

Pengujian model struktural digunakan untuk mengetahui besarnya efek, dapat dilihat pada nilai $\mathrm{R}$-squares pada variabel $\mathrm{Z}$ dan $\mathrm{Y}$ dalam penelitian ini. Ukuran efek dapat dikelompokkan menjadi 3 kategori yaitu lemah $(0,02)$, medium $(0,15)$ dan besar $(0.35)$.

TABLE 4 | Nilai R-Squares

\begin{tabular}{|c|c|c|c|c|}
\hline \multicolumn{5}{|c|}{ R-squared coefficients } \\
\hline $\mathrm{X} 1$ & $\times 2$ & X3 & Z & Y \\
\hline & & & 0.250 & 0.224 \\
\hline
\end{tabular}

Sumber: hasil nilai R-Square pada Warppls 5.0

Dari tabel diatas diketahui yaitu nilai pada variabeel Turover Intention (Y) sebesar 0.224 atau 22,4\% yang berarti pengaruh Job Insecurity (X1), Kepuasan Kerja (X2), dan Stres Kerja (X3) tarhadap Turnover Itention (Y) bisa dikatakan memiliki pengaruh yang medium karena lebih dari 0,15. Variabel Komitmen Organsasi (Z) memiliki nilai R-Squares sebesar 0.250 atau $25 \%$, begitu pula pengaruh dari variabel X1,X2, X3 terhadap Komitmen Organisasi (Z) adalah medium.

\section{Uji hiipotesis}

Hipotesis diterima apabila nilai $\mathrm{p}<0,10$. Dan untuk melihat tingkat signifikansi dengan melihat nilai P-values pada output. Sementara koefisien beta $(\beta)$ merupakan nilai yang menunjukkann besarnya pengaruh antar variabel yang diteliti.

1. Untuk melihat besarnya pengaruh secara tidak langsung (indireect effect) variabel $\mathrm{X} 1, \mathrm{X} 2, \mathrm{X} 3$ terhadap $\mathrm{Y}$ melalui $\mathrm{Z}$ sebagai varibel intervening adalah dengan menjumlahkan koefisien beta $(\beta)$ pengaruh langsung $\mathrm{X}$ terhadap $\mathrm{Z}$ dan pengaruh langsung $\mathrm{Z}$ terhadap $\mathrm{Y}$, sehingga:

a. Indirect Effect

$=$ direct effect $\mathrm{X} 1$ terhadap $\mathrm{Z}+$ direct effect $\mathrm{Z}$ terhadap $\mathrm{Y}$

$=0,24+0,23$

$=0,47$ atau $47 \%$

b. Indirect Effect

$=$ direct effect $\mathrm{X} 2$ terhadap $\mathrm{Z}+$ direct effect $\mathrm{Z}$ terhadap $\mathrm{Y}$

$=0,19+0,23$

$=0,42$ atau $42 \%$

c. Indirect Effect

$=$ direct effect $\mathrm{X} 3$ terhadap $\mathrm{Z}+$ direct effect $\mathrm{Z}$ terhadap $\mathrm{Y}$

$=0,20+0,23$

$=0,43$ atau $43 \%$ 


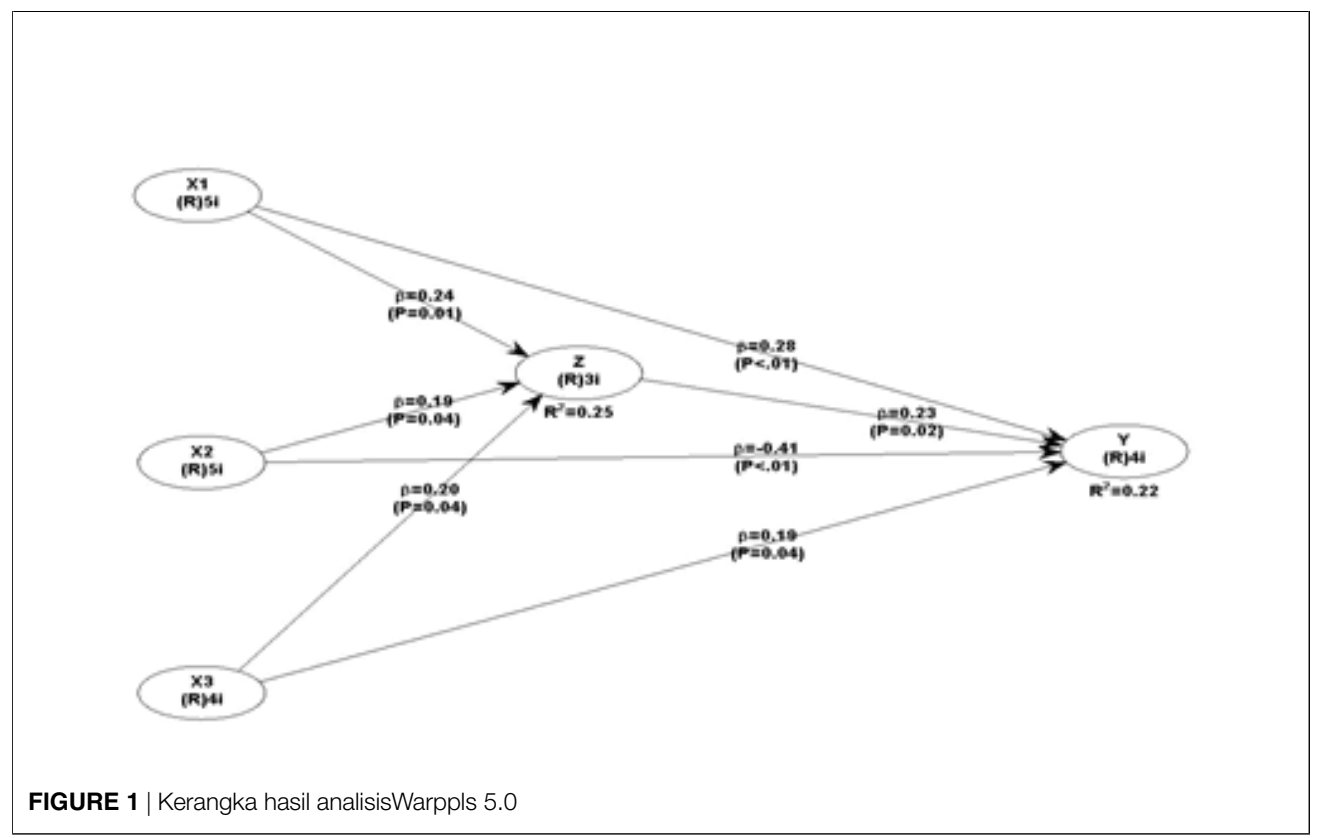

Dari hasil perhitungan diatas, menunjukkan terdapat pengaruh secara tidk langsung antara Job Insecurity (X1) terhdap Turnover Itention (Y) melallui Komitmen Organisasi (Z) sabagai variabel Intervening 0.047 atau $47 \%$ sehingga hipotesis pertama diterima karena terbukti variabel Job Insecurity memiliki pengaruh tidak lansung terhadap Turnover Intention melalui Komitmen Oganisasi $(Z)$ sebagai variabel Intervening.

Dari hasil perhitungan, menunjukkan terdapat pengaruh tidak langsug antara Kepuasan Kerja (X2) terhadap Turnover Intention (Y) melalui Komitmen Organiasi (Z) sebagai variabel Intervening sebesar 0,42 atau $42 \%$ sehingga hipotesis kedua diterima karena terbukti variabel Kepuasan Kerja (X2) memiliki pengaruh tidaak langsung terhadap Turnover Intention (Y) melalui Komitmen Organisasi (Z) sebagai variabel Intervening.

Perhitungan diatas menunjukkan terdapat pengaruh sacara tidak lagsung antara Stres Kerja (X3) terhadap Turnover Intention (Y) melalui Komitmn Organisasi $(\mathrm{Z})$ sebagai variabel Intervening sebesar 0,43 atau $43 \%$ yang berarti hipotesis ketiga diterima karena terbukti variabel Stres Kerja (X3) mimiliki pengaruh secara tidak langsung terhadp Tunover Intention (Y) melalui Komitmenn Organiasi (Z) sabagai variabel Intervening.

\section{Pembahasan}

1. Hipotesis pertama : Terdapat pengaruh secara tdak langsungg Job Insecurity terhadap Turnover Itention melalui Komitmen Organisasi sabagai variabel intervening pada PT Lumina Packaging

Pada pengujian hipotesis ditemukan bahwa Job Insecurity (X1) mmiliki pengaruh secara tidak lansung terhadap Turnover Intention (Y) mlalui Komitmn Organisasi (Z) sebagai variabel intervening yang berarti hipotesis pertama diterima, yang menunjukkan bahwa variabel job insecurity yang dialami karyawan pada perusahaan ini cukup tinggi tetapi tidak serta merta membuat mereka memutuskan untuk langsung keluar dari organisasi ini, melainkan faktor komitmen organisasi karyawan yang menjadi salah 1 faktor penentu yang pada akhirnya menjadi pertimbangan para karyawan untuk memilih akan bertahan lebih lama dalam perusahaan ini atau memilih alternatif pekerjaan lain diluar perusahaan ini.

2. Hipotesis kedua : Terdapat pengaruh secara tidak langsung Kepuasan Kerja tarhadap Turnover Itention melalui Komitmen Organisaasi sabagai variabel intervening pada PT Lumina Packaging

Berdasarkan hasil pengujian hipotesis ditemukan Kepusan Kerja (X2) berpengaruh tidak 
langsung terhadap Trnover Intention (Y) melalui Komiitmen Organisasi (Z) sebagai variabel intervening yang berarti hipotesis kedua diterima. Kepuasan kerja karyawan pada PT Lumina Packaging cukup tinggi dan hal ini meningkatkan komitmen organisasi yang mereka miliki, sehingga membuat mereka bertahan lebih lama dalam perusahaan ini atau bahkan sebaliknya, jika karyawan tidak memiliki komitmen organisaasi yang tinggi mereka cenderung memilih meninggalkann perusahaan ini atau mencari pekerjaan tambahan diluar organisasi ini.

3. Hipotesis ketiga : Terdapat pengaru secara tidak langsung Stres Kerja terhadap Turnoveer Intention melalui Komitmen Organisassi sebagai varibel intervening pada PT Lumina Packaging

Pengujian hipotesis diatas ditemukan Stres Kerja (X3) memliki pengaruh tidak langgsung terhadap Turnover Itention ( $\mathrm{Y}$ ) melalui Komittmen Organisasii $(\mathrm{Z})$ sabagai variabel intervening yang berarti hipotesis ketiga diterima. Yang menunnjukkan adanya permasalahan stres kerja cukup tinggi pada perusahaan ini, namun hal ini tidak selalu membuat para karyawan pada perusahaan ini untuk langsung keluar, melainkan ada faktor komitmen organisasi mereka miliki yang dapat menentukan apakah pada akhirnya karyawan yang bersangkutan memilih untuk tetap memelihara keanggotaan pada perusahaan ini atau mencari alternatif pekerjaan lain diluar perusahaan ini

\section{KESIMPULAN}

1. Job Insecurity (X1) berpengaruh sacara tiidak langsung terhadap Turnover Itention (Y) melalui Komitmen Orgaisasi (Z) sebagai Variabel Intervening paada PT Lumina Packaging

2. Kepuasan Kerja (X2) berpengaruh secara tidak langsung terhadap Turnover Intention (Y) mlalui Komitmen Organiisasi (Z) sabagai Variabel Intervening pada PT Lumina Packaging

3. Stres Kerja (X3) berrpengaruh secara tidak lansung terhadap Tunover Intention (Y) mlalui Komitmen Organisasii (Z) sabagai Variabel Intervening pada PT Lumina Packaging

\section{UCAPAN TERIMA KASIH}

Rasa syukur dan terima kasih penulis ucapkan sebesar-besarnya pada pihak perusahaan PT Lumina Packaging yang bersedia memberi izin penelitian dan berkenan menjadi objek penelitian ini, juga para karyawan yang berkenan menjadi responden. Terima kasih juga ditujukan kepada dosen pembimbing penulis yaitu Ibu Sumartik yang berkenan membimbing dan meluangkan waktunya serta selalu memberi motivasi. Semoga penelitian ini bisa bermanfaat.

\section{REFERENSI}

Arshadi, Nasrin dan Hojat Damiri. 2013. "The Relationship of Job Stress with Turnover Intention and Job Performance: Moderating Role of OBSE” Journal of Procedia-Social and Behavioral Sciences 84 (2013) 706-710. Cyprus: Elsevier Ltd

1. Bangun, Wilson. 2012. Manajemen Sumber Daya Manusia. Erlangga: Bandung

2. Cinar, Orhan. Fatih Karcioglu dan Imran Aslan. 2014. "The Relationship Among Organizational Cynism, Job Insecurity and Turnover Intention: A Survey Study in Erzurum/Turkey" Journal Procedia-Social and Behavioral Sciences 150 (2014) 429-437. Turkey: Elsevier Ltd

3. Elmi, Farida. 2018. Telisik Manajemen Sumber Daya Manusia. Edisi Asli, Mitra Wacana Media: Jakarta

4. Hamali, Arif Yusuf. 2018. Pemahaman Manajemen Sumber Daya Manusia. Edisi 3. CAPS (Center for Academic Publishing Service): Yogyakarta

5. Handoko, T.Hani. 2014. Manajemen Personalia \& Sumberdaya Manusia. Edisi 2. BPFE: Yogyakarta

6. Iskandar \& Yuhansyah. 2018. Pengaruh Motivasi \& Ketidakamanan Kerja Terhadap Penilaian Kerja yang Berdampak kepada Kepuasan Kerja. Media Sahabat Cendekia: Surabaya 
7. Kartono. 2017. Personality, Employee Engagement, Emotional Intellegence, Job Burnout, Pendekatan dalam Melihat Turnover Intention. Deepublish: Sleman

8. Latan, Hengky dan Imam Ghozali . 2016. Partial Least Squares Konsep, Metode dan Aplikasi Menggunakan Program Warppls 5.0. Edisi 3. Badan Penerbit Universitas Diponegoro: Semarang

9. Qureshi, Muhammad Imran et all. 2013. "Relationship Between Job Stress, Workload, Environment and Employees Turnover Intention: What We Know, What Should We Know" dalam World Applied Sciences Journal 23 (6): 764-770,2013, Islamabad: IDOSI Publications

10. Septiani, Ni Ketut dan I Komang Ardana. 2016. "Pengaruh Job Insecurity dan Stres Kerja terhadap Turnover Intention Karyawan pada Hotel Asana Agung Putra Bali” dalam E-Jurnal Manajemen Unud Volume 5 (hlm. 6429-6456). Bali: E-Jurnal Manajemen Unud

11. Sugiyono. 2016. Metode Penelitian Manajemen Pendekatan Kuantitatif, Kualitatif, Kombinasi, Penelitian Tindakan, Penelitian Evaluasi. Edisi 5. Alfabeta,cv : Bandung

12. Sujarweni, V. Wiratna. 2015. Metodologi Penelitian Bisnis \& Ekonomi. Edisi Asli. Pustaka Baru Press: Yogyakarta

13. Tnay, Evelyn et all. 2013. “The Influence Of Job Satisfaction and Organizational Commitment on Turnover Intention" Journal of Procedia-Social and Behavioral Sciences 97 (2013) 201208. Sarawak: Elsevier Ltd

14. Umam, Khaerul. 2018. Perilaku Organisasi. Bandung: CV Pustaka Setia

15. Vujicic, Dunja et all. 2014. "the Realtionship between Job Insecurity, Job Satisfaction and Organizational Commitment among Employees in the Tourism Sector in Novi Sad" Journal of Economic and Industial Democracy (hlm. 1-20). Serbia: SAGE Publishing

16. Wibowo, I Gede Putro. Gede Riana dan Made Surya Putra. 2015. "Pengaruh Stres Kerja Terhadap Kepuasan Kerja dan Komitmen Organisasional Karyawan" dalam E-Jurnal Ekonomi dan Bisnis Universita s Udayana 4.02 (hlm. 125-145). Bali: E-Jurnal Manajemen Unud

17. Yuda, Ida Bagus Dwihana Parta dan I Komang Ardana. 2017. “Pengaruh Kepuasan Kerja dan Stres Kerja terhadap Turnover Intention pada Karyawan Hotel Holiday Inn Express" dalam E-Jurnal Manajemen Unud Volume 6 (hlm. 5319-5347). Bali: E-Jurnal Manajemen Unud

Conflict of Interest Statement: The authors declare that the research was conducted in the absence of any commercial or financial relationships that could be construed as a potential conflict of interest.

Copyright $\odot 2020$ Wulanfitri, and Indayani. This is an openaccess article distributed under the terms of the Creative Com- mons Attribution License (CC BY). The use, distribution or reproduction in other forums is permitted, provided the original author(s) and the copyright owner(s) are credited and that the original publication in this journal is cited, in accordance with accepted academic practice. No use, distribution or reproduction is permitted which does not comply with these terms. 